\title{
Perancangan Papan Informasi Digital Berbasis Web pada Raspberry pi
}

\author{
Rizal Panuntun, Adian Fatchur Rochim, Kurniawan Teguh Martono \\ Jurusan Sistem Komputer Fakultas Teknik Universitas Diponegoro \\ Jln. Prof. Sudharto, Tembalang, Semarang, Indonesia.
}

\begin{abstract}
Digital signage is information boards migrate from conventional forms to digital form. Form of digital signage used in computer by connecting to monitor to display the information. Digital notice board (digital signage) puts a digital-based information services in one direction.

Many digital signage applications appear with the development of information technology. Unfortunately, if used as a digital signage devices, the implementation of existing digital signage applications using a desktop computer is unefficient. Signage applications that developed to be implemented on a single board computers such as raspberry-pi is still rare. In that case, there are any idea to implement a mini computer raspberry-pi as digital signage devices. Mini computer raspberry-Pi was chosen because of its small size and power saving. so it can be efficient and flexible than a regular desktop computer.

Forming of this thesis includes designing web server using $P H P$ and MYSQL and raspberry pi configuration. The results of this research is to implement digital signage in raspbeery pi that produce a web-based digital information boards that efficient and power saving.
\end{abstract}

Keywords: digital signage, information, raspberry-pi

\section{Pendahuluan}

\subsection{Latar Belakang}

nformasi merupakan kebutuhan yang sangat penting. Teputusan yang tepat bisa diambil jika memiliki informasi yang tepat pula. Pemilihan media informasi yang kurang tepat mengakibatkan informasi yang dimaksud tidak tersampaikan secara benar kepada para konsumen.

Papan Informasi digital (Digital Signage) merupakan salah satu media elektronik yang saat ini sering digunakan untuk memberikan informasi yang dibutuhkan baik dalam dunia industri, lembaga pemerintahan maupun dalam dunia pendidikan. Papan pengumuman digital (digital signage) adalah Sebuah layanan informasi berbasis digital satu arah. Komponen sebuah digital signage teridiri dari sebuah server, router, pc serta monitor

Digital signage pada tugas akhir ini menggunakan raspberry-pi yaitu komputer mini yang memerlukan daya rendah. Raspberry-pi akan menampilkan informasi dari sebuah web server yang diakses melalui sebuah browser dan ditampilkan pada sebuah monitor. Komputer raspberry-pi dipilih karena bentuknya yang kecil seukuran kartu kredit sehingga tidak memerlukan tempat yang luas sehingga lebih fleksibel serta memerlukan daya yang lebih sedikit daripada menggunakan personal komputer.

\subsection{Tujuan Penelitian}

Tujuan dari penelitian ini untuk mengimplementasikan komputer raspberry-pi sebagai papan informasi berbasis web untuk mempermudah memberikan informasi dan layanan yang ada pada Program Studi Teknik Sistem Komputer Universitas Diponegoro.

\subsection{Batasan Masalah}

Batasan Masalah dalam penulisan tugas akhir ini memiliki batasan pada permasalahan sebagai berikut:

a) Papan informasi digital ini menggunakan raspberry pi.

b) Perancangan web sever menggunakan PHP dan MySQL.

c) Komputer raspberry-pi yang digunakan adalah raspberry-pi model $\mathrm{B}$, dengan sistem operasi debian wheezy.

d) Papan Informasi ini digunakan pada dilingkungan kampus Program Studi Teknik Sistem Komputer Universitas Diponegoro.

\section{Landasan Teori}

\subsection{Digital Signage}

Papan pengumuman digital (digital signage) adalah Sebuah layanan informasi berbasis digital satu arah. efektifitas digital signage sangat dipengaruhi oleh strategi penyampaian pesan layanan ini biasanya digunakan di beberapa tempat strategis dan dimana kerumunan orang berada.

Digital Signage adalah media yang penyampain pesannya terarah (narrowcast), yang berbeda dari media televisi, yang penyampaian pesannya secara meluas (broascast). Konsep narrowcast inilah yang pada akhirnya akan mempengaruhi bagaimana strategi penyampaian pesan diterapkan pada digital signage. Digital signage ini memanfaatkan teknologi layar datar seperti LCD, LED, atau plasma yang diproyeksikan untuk menampilkan konten multimedia, beberapa keuntungan menggunakan digital signage dibandingkan menggunakan fixed advertisement:

$>$ Eye contact catching, konten yang dinamis mempunyai kekuatan yang lebih untuk menarik perhatian audiens. 
> Right place, right time, digital signage memperbarui konten yang disesuaikan pada waktu dan situasi tertentu. Pesan dapat diarahkan sesuai dengan demographic audiens.

$>$ Save cost and time, mengkolaborasikan berbagai jenis media konvensional ke dalam satu bentuk media (Digital Signage konten) yang lebih menarik dan atraktif.

$>$ Maximized return investment sebagai terminal profit center dengan menjual ruang advertisement untuk supplier atau relasi bisnis

$>$ Corporate Images, penggunaan IT dan display yang dipadukan, memberikan kesan modern yang pada akhirnya dapat meningkatkan prestise perusahaaan. [1]

Digital signage mengarah kepada electronically controlled signs yang dapat di-update/diperbaharui secara cepat, dengan biaya yang murah, dan pesan yang disampaikan dapat terkirim ke sebuah display atau banyak display dalam satu waktu secara bersamaan. [2]

\subsection{MySQL}

MYSQL merupakan database yang paling popular digunakan untuk membangun aplikasi web yang menggunakan database sebagai sumber dan pengelola datanya. PhpMyAdmin merupakan bagian untuk mengelola basis data MySQL yang ada di komputer dengan tampilan GUI. Dengan phpMyAdmin, seseorang dapat membuat database, membuat tabel, mengisi data, dan lain-lain dengan mudah, tanpa harus menghafal baris perintahnya.

\section{$2.3 \mathrm{PHP}$}

PHP merupakan bahasa pemrograman berbentuk script yang ditempatkan dalam server dan diproses di server yang pertama kali dibuat oleh Rasmus Lerdorf pada tahun 1995 [7]. PHP adalah bahasa open source yang dapat digunakan di berbagai mesin (linux, unix, windows) dan dapat dijalankan secara runtime melalui console serta juga dapat menjalankan perintah-perintah sistem.PHP adalah bahasa scripting yang menyatu dengan HTML dan dijalankan pada server side.

\subsection{Codeingniter}

CodeIgniter adalah aplikasi open source yang berupa framework dengan model MVC (Model, View, Controller) untuk membangun website dinamis dengan menggunakan PHP. CodeIgniter memudahkan developer untuk membuat aplikasi web dengan cepat dan mudah dibandingkan dengan membuatnya dari awal [8].

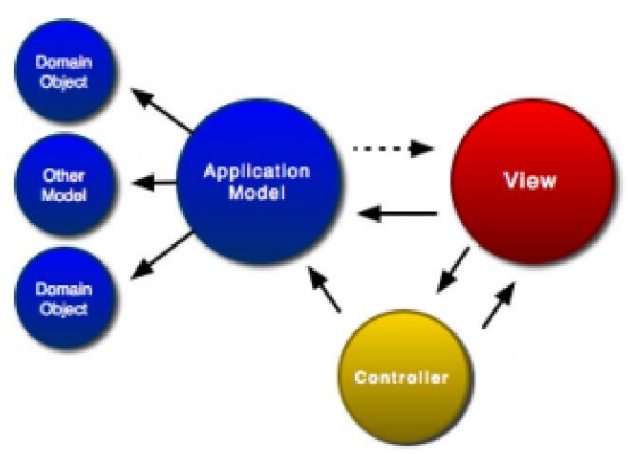

Gambar 2.1 Konsep MVC
Framework adalah suatu kerangka kerja yang berupa sekumpulan folder yang memuat file-file php yang menyediakan class libraries, helpers, plugins dan lainya. Framework menyediakan konfigurasi dan teknik coding tertentu. Codeigniter adalah php framework yang awalnya ditulis oleh Rick Ellis, pendiri dan CEO EllisLab.com, perusahaan yang mengembangkan codeigniter.

\subsection{Raspberry pi}

Raspberry Pi (juga dikenal sebagai RasPi) adalah sebuah SBC (Single Board Computer) seukuran kartu kredit yang dikembangkan oleh Yayasan Raspberry Pi di Inggris (UK)

Raspberry Pi menggunakan system on a chip (SoC) dari Broadcom BCM2835, juga sudah termasuk prosesor ARM1176JZF-S $700 \mathrm{MHz}$, GPU VideoCore IV dan RAM sebesar $256 \mathrm{MB}$.

Tabel 2.1 Tabel Spesifikasi Rpi

\begin{tabular}{|c|c|}
\hline Komponen & Keterangan \\
\hline SoC & $\begin{array}{llllll}\text { Broadcom BCM2835 } & \text { (CPU, GPU, DSP, and } \\
\text { SDRAM) } & & & & & \\
\end{array}$ \\
\hline $\mathrm{CPU}$ & $700 \mathrm{MHz}$ ARM1L76JZF-S core (ARM6 family) \\
\hline GPU & $\begin{array}{c}\text { Broadcom VideoCore IV, OpenGL ES 2.0, } \\
1080 \text { p30 h.264/NPEG-4 AVC high-profile decoder }\end{array}$ \\
\hline Memory & $512 \mathrm{MB} / 256 \mathrm{MB}$ (shared with GPU) \\
\hline USB 2.0 & 2 (via integrated USB hub) \\
\hline Video Output & $\begin{array}{l}\text { - Composite RCA (PAL \& NTSC), HDMI (rev } 1.3 \\
\& 1.4 \text { ), raw LCD Panels via DSI } \\
\text { - } 14 \text { HDMI resolutions from } 640 \times 350 \text { to } \\
1920 \times 1200 \text { plus various PAL and NTSC } \\
\text { standards }\end{array}$ \\
\hline Audio Output & $3.5 \mathrm{~mm}$ jack, HDM \\
\hline On Board Storage & SD / MMC / SDIO card slot \\
\hline On Board Network & 10/100 Ethemet (RJ45) \\
\hline $\begin{array}{ll}\text { Low } & \text { Level } \\
\text { Peripheral } & \end{array}$ & $\begin{array}{l}8 \times \text { GPIO, LART, I² bus, SPI bus with two chip } \\
\text { selects, }+3.3 \mathrm{~V},+5 \mathrm{~V}, \text { ground }[58][63]\end{array}$ \\
\hline Powe & 7001 \\
\hline
\end{tabular}

Raspberry Pi belum mendukung fitur POE. Raspberry Pi bisa diaktifkan menggunakan konektor micro-USB yang terdapat pada sisi kiri bawah circuit board.

\section{Perancangan Sistem}

\subsection{Perancangan Papan Informasi.}

Aplikasi papan informasi adalah perangkat lunak berbasis web, di implementasikan di localhost dan ditampilkan pada LCD TV. Perancangan pembuatan aplikasi papan informasi berbasis web ini akan dibagi menjadi dua tahap, yang pertama adalah menyiapkan komputer raspberry dan tahap kedua menyiapkan web server. Kedua perangkat ini akan dihubungkan ke sebuah jaringan lokal. Untuk memudahkan perancangan. maka maka dibuat diagram alir seperti gambar 3.1 


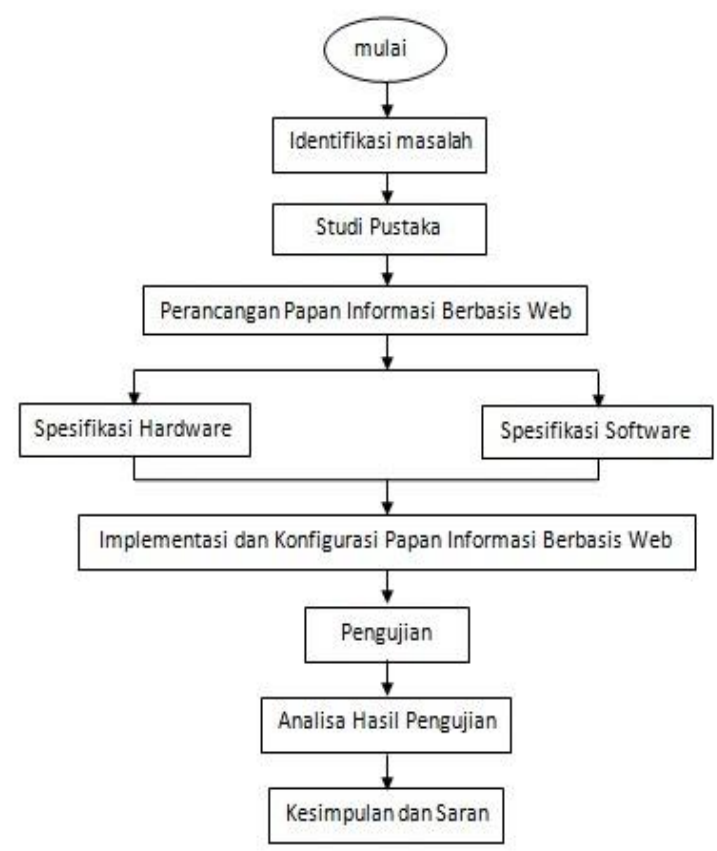

Gambar 3.1 Diagram Alir perencanaan dan implementasi

Perancangan ini menggunakan komputer raspberry pi, monitor LCD TV serta sebuah web server untuk membangun layanan papan informasi berbasis web pada program studi Teknik Sistem Komputer Universitas Diponegoro. Komputer raspberry pi terkoneksi dengan webserver melalui jaringan lokal.

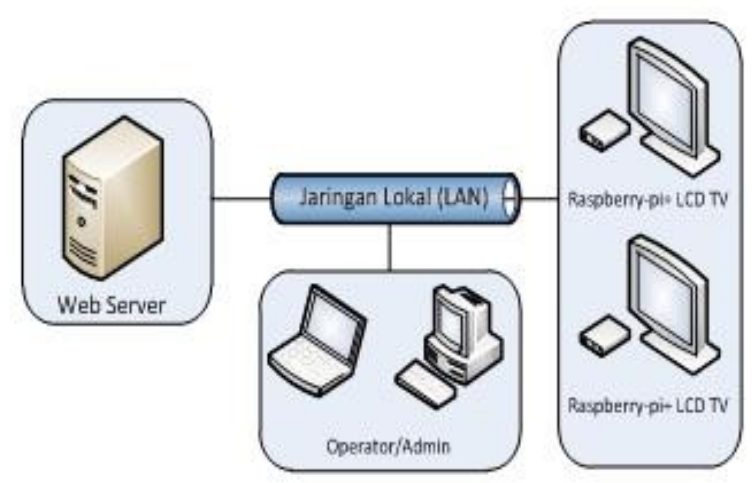

Gambar 3.2 Skema perancangan digital signage berbasis web

\subsection{Perangkat Pengembangan}

\subsubsection{Spesifikasi Hardware}

Spesifikasi hardware yang digunakan dalam pembuatan papan informasi berbasis web ini adalah sebagai berikut :

$>$ Laptop Intel Core i3 2,4 GHz Memory 2 GB

$>$ Raspberry Pi type B

$>$ Kabel serial CA-42

$>$ Kabel HDMI

$>$ Kabel UTP

$>$ Monitor LCD/LED TV

\subsubsection{Spesifikasi Software}

Perangkat lunak software yang digunakan dalam pembuatan papan informasi berbasis web pada raspberry pi:

$>$ Raspibian Wheezy

$>$ Win32DiskImager

$>$ Browser

$>$ Xampp

$>$ Ms Visio 2007

$>$ Framework Code Igniter

$>$ Netbeans IDE 7.3.1

$>$ Heidi $S Q L$

\subsection{Analisa kebutuhan}

Perancangan papan informasi berbasis web pada raspberry pi yang dibangun bersifat object oriented (berorientasi objek) dengan menggunakan Unified Modeling Language (UML) sebagai bahasa pemodelan dan menggunakan framework codeigniter.

Analisa kebutuhan sistem ini adalah fase analisis untuk memahami kebutuhan sistem secara mendalam. Kebutuhan Sistem ini dibagi menjadi 2 jenis, yaitu kebutuhan fungsional dan kebutuhan non fungsional.

Analisis kebutuhan fungsional adalah kebutuhan yang berisikan proses-proses kebutuhan yang wajib ada pada sistem.

Analisis kebutuhan non fungsional adalah fitur tambahan yang bisa menunjang kinerja sistem dan bisa membuat sistem menjadi lebih baik.

\subsection{Analisa Perilaku Sistem}

Analisa perilaku sistem aplikasi papan informasi digital digambarkan dengan use case diagram, sequence diagram dan class diagram.

Use-case diagram merupakan model diagram UML yang digunakan untuk menggambarkan requirement fungsional yang diharapkan dari sebuah sistem dengan mendefinisikan skenario penggunaan yang disepakati antara pemakai dan pengembang.

Class diagram adalah diagram yang menggambarkan struktur dan hubungan antar objek-objek yang ada pada sistem. Struktur itu meliputi atribut-atribut dan metodemetode yang ada pada masing-masing class. Hubungan dari masing-masing class yang ada digambarkan seperti pada gambar berikut.

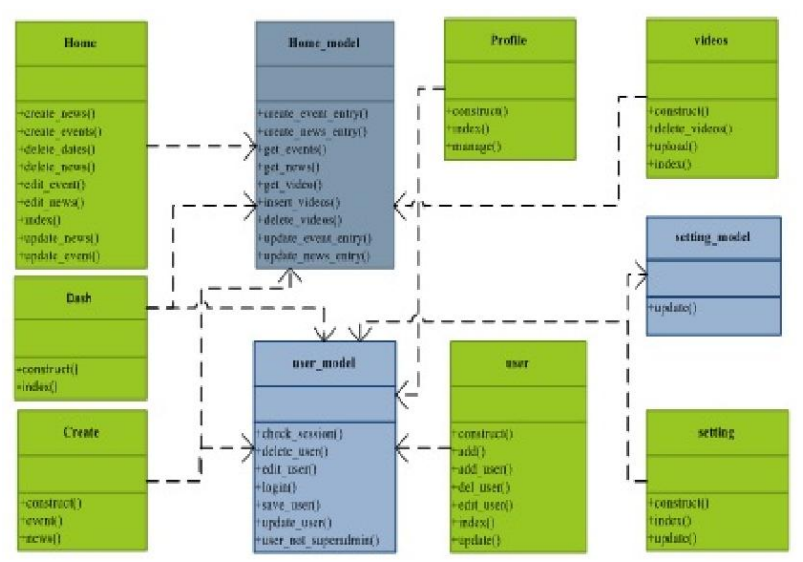

Gambar 3.3 Class Diagram 
Sequence diagram adalah suatu diagram yang memperlihatkan atau menampilkan interaksi-interaksi antar objek setiap use case dalam urutan waktu. Sequence Diagram digunakan untuk menggambarkan skenario atau rangkaian langkah-langkah yang dilakukan sebagai sebuah respon dari suatu even untuk menghasilkan output tertentu

\subsection{Tahapan Implementasi}

Tahap ini merupakan tahap dimana desain diterjemahkan kedalam bentuk mesin yang bisa dibaca. Tahap ini membuat dan mengintegrasikan kode program dengan desain interface yang telah dibuat.

Pembangunan aplikasi ini menggunakan data-data yang disimpan dalam database menggunakan MySQL sebagai media penyimpanannya. Tabel-tabel ini nantinya akan digunakan untuk menyimpan informasi mengenai seluruh komponen.

\subsubsection{Perancangan Data}

Berisi daftar dari tabel yang akan digunakan sebagai media penyimpanan data (Data Storage) untuk basis data yang dipergunakan oleh papan informasi berbasis web. Daftar table yang akan digunakan tersaji pada tabel 3.1.

Tabel 3.1 tabel basis data yang digunakan

\begin{tabular}{|c|c|c|}
\hline Nama Tabel & Primary Key & Data Storage \\
\hline users & id_users & Dbsignage \\
\hline news & id_news & Dbsignage \\
\hline dates & id_date & Dbsignage \\
\hline setting & id_setting & Dbsignage \\
\hline Kode_level & kd_video & Dbsignage \\
\hline videos & id_video & Dbsignage \\
\hline
\end{tabular}

\subsection{2 perancangan Antarmuka}

Perancangan antarmuka akan menunjukan bagaimana administrator dan operator dapat berinteraksi dengan sistem. Tampilan antar muka yang dibuat berupa formform.

\section{Pengujian dan Analisis}

Sistem papan informasi digital disimpan pada sebuah komputer server yang sudah terinstall apache sebagai web server, MySQL sebagai DBMS, dan framework codeigniter. Pada sisi komputer client menggunakan komputer mini raspberry pi model B dengan sistem operasi raspbian wheezy. Sistem dibuat dengan sistem tersentralisasi, yaitu dengan meletakkan aplikasi dan basis data pada sebuah server. Raspberry pi bertindak sebagai client sekaligus sebagai player untuk menampilkan informasi kepada mahasiswa. Pengujian akan dilakukan terhadap semua elemen-elemen sistem baik aplikasi web papan informasi serta pengujian raspberry pi.

\subsection{Implementasi Basis data}

Langkah awal dalam implementasi adalah pembuatan database berdasarkan pada tabel-tabel yang telah dirancang. Aplikasi papan informasi berbasis web mengunakan basis data MySQL untuk media penyimpanan datanya. Langkah pertama adalah membuat database, dengan nama signage yang terdiri dari enam buah tabel yaitu: user, dates, news, setting, kode level dan videos. Setiap tabel memiliki primary key berupa id.

\subsection{Implementasi Webserver}

Implementasi aplikasi ini menggunakan bahasa pemrograman PHP, framework codeigniter serta menggunakan MySQL untuk basis datanya. Aplikasi papan informasi ini dibuat sedemikian rupa sehingga memudahkan user dalam penggunaan disertai dengan antarmuka yang dinamis. Sistem papan informasi digital disimpan pada sebuah server yang sudah ter-install Apache HTTP Server 2.2.4 sebagai web server, MySQL sebagai DBMS, dan framework PHP Code Igniter. Papan informasi diletakan pada document root web server (htdocs). Sistem dibuat dengan sistem tersentralisasi, yaitu dengan meletakkan aplikasi dan basis data pada sebuah server. Client mengakses sistem informasi menggunakan web browser dengan mengakses URL http://192.168.1.2/digital.

\subsection{Tahapan Implementasi Raspberry pi}

Tahap ini merupakan tahap mempersiapkan komputer mini raspberry-pi supaya mampu menampilkan aplikasi web yang sudah dibuat. Tahapan ini meliputi beberapa konfigurasi seperti:
$\checkmark \quad$ Instalasi Sistem Operasi
$\checkmark$ konfigurasi Jaringan
$\checkmark \quad$ Instalasi Gnash pada Raspberry-Pi

\subsection{Konfigurasi Sistem}

Untuk menampilkan informasi yang ada pada papan informasi dgital berbasis web, Raspberry pi harus terhubung dengan layar monitor yang yang memiliki port HDMI karena raspberry pi tidak memiiki port VGA yang umumnya digunakan pada komputer biasa. Raspberry pi memiliki port HDMI yang bisa dihubungkan ke port VGA menggunakan converter, namun jika menggunakan converter raspberry pi membutuhkan arus listrik yang lebih besar dan lebih stabil. Konfigurasi sistem dapat dimodelkan seperti gambar 4.1

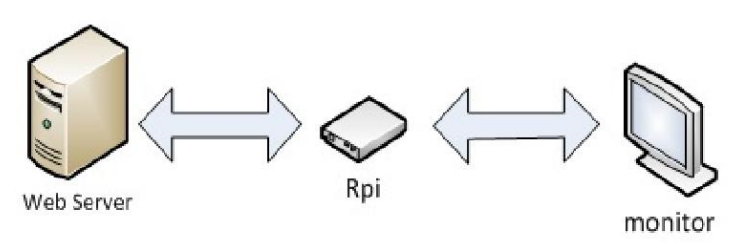

gambar 4.1 permodelan sistem klien

Setelah client dan server siap, keduanya harus saling dihubungkan kedalam satu jaringan yang dapat saling berkomunikasi.

\subsection{Materi Pengujian Papan Informasi Berbasis Web}

Pengujian ini digunakan teknik pengujian Black Box, antara lain :

a) Digunakan untuk menguji fungsi-fungsi khusus dari perangkat lunak yang dirancang. 
b) Kebenaran perangkat lunak yang diuji hanya dilihat berdasarkan keluaran (output) yang dihasilkan dari data atau kondisi masukan yang diberikan untuk fungsi yang ada tanpa melihat bagaimana proses untuk mendapatkan keluaran tersebut.

c) Dari keluaran yang dihasilkan, kemampuan program dalam memenuhi kebutuhan pemakai dapat diukur sekaligus dapat diketahui kesalahannya.

Pengujian yang dilakukan pada sisi web server papan informasi digital meliputi semua elemen baik tampilan maupun fungsi dari tiap elemen sistem. Materi pengujian papan informasi berbasis web antara lain:

1. Tampilan login

2. Tampilan dashboard

3. Mengunggah Video

4. Menghapus Video

5. Tampilan pengaturan password

6. Tampilan manajemen account

7. Tampilan halaman utama

\subsection{Pengujian CPU dan Memori Rapberry pi}

Pengujian ini dilakukan untuk mengetahui dan mengamati performa dari raspberry pi berupa pemakaian memory dan CPU pada saat papan informasi berjalan.

Pengujian ini menggunakan aplikasi monitoring sistem yang terdapat pada sistem operasi raspibian wheezy yaitu aplikasi TOP. Aplikasi ini dapat memonitor sistem yang berjalan dan berapa task yang sedang dikerjakan, pemakaian CPU dan pemakaian memori.

Pengujian CPU dan memori dilakukan pada saat browser aktif. Pengambilan data diambil sebanyak sepuluh kali dengan interval waktu 3 detik, maka dihasilkan data seperti tabel 4.1

Tabel 4.1 Penggunaan cpu dan memory

\begin{tabular}{|c|c|c|}
\hline \multirow{2}{*}{ No } & \multicolumn{2}{|c|}{$\begin{array}{c}\text { Penggunaam resources pada saat } \\
\text { browser aktif }\end{array}$} \\
\cline { 2 - 3 } & $\begin{array}{c}\text { Penggunaan } \\
\text { CPU }\end{array}$ & $\begin{array}{c}\text { Penggunaan } \\
\text { Memory }\end{array}$ \\
\hline 1 & $53.7 \%$ & $40,2 \%$ \\
\hline 2 & $61.9 \%$ & $40,7 \%$ \\
\hline 3 & $40.6 \%$ & $37,7 \%$ \\
\hline 4 & $77,4 \%$ & $38,7 \%$ \\
\hline 5 & $68,2 \%$ & $38,5 \%$ \\
\hline 6 & $49.9 \%$ & $39,7 \%$ \\
\hline 7 & $56,3 \%$ & $42,1 \%$ \\
\hline 8 & $46.6 \%$ & $37,7 \%$ \\
\hline 9 & $51,3 \%$ & $38,7 \%$ \\
\hline 10 & $74,6 \%$ & $48,4 \%$ \\
\hline $\begin{array}{l}\text { Rata- } \\
\text { rata }\end{array}$ & $58,06 \%$ & $40,24 \%$ \\
\hline
\end{tabular}

\subsection{Analisis Hasil Uji Kinerja Sistem Papan Informasi}

\section{Digital.}

Eksperimen yang dilakukan mengujikan fitur-fitur utama yang dimiliki oleh sistem serta responbilitas dari pengendalian client dan server juga akan diuji. Pengujianya meliputi:

- Responbilitas

- Informasi berbasis teks dengan dan tanpa jquery

- Informasi berbasis video

Uji coba ini ditujukan untuk mengujikan kemampuan sistem papan informasi pada raspberry pi sebagai client

Uji coba ini ditujukan untuk mengujikan kemampuan sistem papan informasi pada raspberry pi sebagai client untuk menampilkan informasi yang ditampilkan oleh komputer server. Saat dilakukan ujicoba komputer pada client menggunakan raspberry pi mampu menampilkan informasi yang ada pada komputer server. Hasil ujicoba kinerja komputer client pada raspberry pi disajikan pada tabel 4.9.

Tabel 4.2 tabel pengujian responbilitas

\begin{tabular}{|c|c|}
\hline Butir pengujian & Raspberry pi \\
\hline $\begin{array}{c}\text { Menampilkan informasi } \\
\text { teks tanpa jquery }\end{array}$ & Bisa \\
\hline $\begin{array}{c}\text { Menampilkan informasi } \\
\text { teks dengan jquery }\end{array}$ & $\begin{array}{c}\text { Bisa } \\
\text { (patah-patah) }\end{array}$ \\
\hline $\begin{array}{c}\text { Menampilkan informasi } \\
\text { video }\end{array}$ & Gagal menampilkan video. \\
\hline responsivitas & \pm 1 menit \\
\hline
\end{tabular}

Hasil pengujian diatas raspberry pi dapat menampilkan informasi yang ada pada komputer server, namun karena rosources dan kecepatan yang dimiliki oleh raspberry pi terbatas sehingga kurang responsif. Besarnya memori dan CPU yang dimiliki oleh raspberry pi model B yang kecil menjadikan raspberry pi tidak maksimal dalam menampilkan informasi yang ada didalam web server. Browser yang ada pada raspberry pi belum mendukung HTML 5, flash player serta CSS 3 sehingga membutuhkan package tambahan. Kapasitas memori dan CPU terbatas pada raspberry pi model B belum mampu menjalankan dan menampilkan video yang ada pada papan informasi. Sering kali raspberry pi mengalami hang pada saat menampilkan informasi karena terbatasnya resources.

\subsection{Kesimpulan}

\section{Penutup}

1. Sistem papan informasi digital berbasis web dirancang menggunakan bahasa pemrograman $P H P, \quad S Q L$ sebagai basis datanya, framework codeigniter, dan komputer mini raspberry pi.

2. Browser pada raspberry pi belum mensupport HTML 5, flash palayer dan CSS 3.

3. Kinerja papan informasi digital pada raspberry pi kurang baik bila dibandingkan dengan komputer windows.

\subsection{Saran}

1. Papan informasi digital ini dapat dikembangkan menjadi sistem yang lebih besar dan diintegrasikan dengan sistem penjadwalan maupun sia yang ada di fakultas maupun jurusan. 
2. Papan informasi digital ini diletakan di tempattempat yang strategis dan ramai.

3. Penelitian berikutnya lebih baik berorientasi pada pengembangan papan informasi digital khusus utuk single board raspberry pi karena kebutuhan yang khusus serta kecepatan dan reosurce yang terbatas pada raspberry pi.

\section{Daftar Pustaka}

[1] Rusell, J.2012. "Digital Signage" (USA: Aurbach Publications, 2009).

[2] Ihsan, M. 2011. "Introduce XIBO Digital Siganage." Dari http://www.slideshare.net/xibodigital-signage. Diakses januari 2014.

[3] Hantono B Sunarfi. 2014. Analisis Unjuk Kerja Aplikasi Digital Signage XIBO pada SBC Raspberry Pi. Yogyakarta: Universitas Gadjah Mada 2014.
[4] M. Arif, Kualitas Pelayanan Publik di Bandara Internasional Sultan Hasanuddin Makassar, Makassar: Sekolah Pascasarjana UNHAS, 2011.

[5] Nur Mufmin. 2012. "Membangun papan informasi Jamsostek berbasis web" Dari http://elib.unikom.ac.id/kp/papan-informasijamsostek. Diakses Januari 2014.

[6] Kadir, Abdul. 2009. From Zero to a Pro Membuat Aplikasi Web. Yogyakarta: Andi Publisher.

[7] Wahyono, Teguh.2005. PHP Triad Fundamental. Yogyakarta: Gava Media

[8] Ardana, YM Kusuma. 2012. Pemrogaman PHP Codeigniter Black Box. Jakarta: Jasakom.

[9] Saputra, Agus. 2011. Trik Kolaborasi Codeigniter dan jQuery. Yogyakarta: Lokomedia.

[10] Kadir, Abdul. 2009. Mudah Mempelajari Database MySQL. Yogyakarta: Penerbit Andi. 